\title{
Students' Sense of Coherence, Study Engagement and Self-Efficacy in Relation to their Study and Employability Satisfaction
}

\author{
Melinde Coetzee \\ Rudolf M. Oosthuizen \\ University of South Africa
}

\begin{abstract}
Address correspondence to Prof Melinde Coetzee, Department of Industrial and Organisational Psychology, University of South Africa, PO Box 392, Pretoria, Gauteng, South Africa, 0003. E-mail: coetzm1@unisa.ac.za
\end{abstract}

This study reports on students' sense of coherence, study engagement and self-efficacy in relation to their satisfaction with current studies and employability. Participants included a convenience sample of 127 employed adult learners enrolled for third year level open distance learning (ODL) undergraduate studies in industrial and organisational psychology. A quantitative survey approach was followed, collecting primary data. Data analysis consisted of correlational and standard multiple regression analyses. The results revealed students' dedication to and perceived meaningfulness of undergraduate studies as significant predictors of their study and employability satisfaction. The participants' self-efficacy did not relate significantly to their satisfaction with their current studies and employability. These findings contribute new knowledge that could be used to inform the design of learner support interventions aimed at increasing students' motivational levels in the open distance learning context.

Keywords: sense of coherence, study engagement, self-efficacy, study satisfaction, employability satisfaction

Increasing student retention and success rates in the South African higher education context has become a key challenge (Strydom, Kuh, \& Mentz, 2010). In the higher education open distance learning (ODL) institutional context, the pass and throughout rates of students has become a major concern (Prinsloo \& Subotzky, 2011). This concern exists in spite of ODL providing open access to and flexible learning options supported by a student-centred approach in constructing learning programmes and supporting students to enable them to succeed (Pityana, 2009). Although ODL institutions generally endeavour to ensure access to and affordability of learning, they face the challenge of addressing national anxieties about drop-out, success and through-put rates which affect the supply of specialised knowledge and expertise to industry, that is, students who are regarded as being employable (Pityana, 2009).

One of the major contributing factors impacting on students' success appears to be unpreparedness for the rigorous higher educational learning standard which is compounded by their unpreparedness to deal with the increasingly complexities of various life circumstances competing for their time, energy and well-being (Prinsloo \& Subotzky, 2011). More recently, student absence from final examinations has been pointed out as another key factor affecting student pass and throughput rates in the ODL institutional context. A survey conducted by Tladi (2009) at a South African higher education ODL institution, indicated non-academic, psychological and metacognitive as factors impacting students' absence from the final examinations. The findings indicated that unpreparedness for the examination was a major factor, mostly resulting from a lack of confidence and motivation leading to not spending enough time on their preparation for the examination. Other factors included a general lack of interest in the study material, and the course enrolled for not being relevant to their future work or careers (Tladi, 2009).
In an increasingly unpredictable South African labour market, students view their employability, and its continued management, as a crucial issue in their transition from higher education to the labour market. Students' interest and active engagement in their studies, and general satisfaction with their studies have now become important to their perceptions of being employable (Pool \& Sewell, 2007; Tomlinson, 2007). The concerns about employability, in a highly competitive, more turbulent and uncertain employment context (Pool \& Sewell, 2007) warrant the importance of investigating the factors that impact students' satisfaction, confidence, motivational levels, and their willingness to engage with more interest in the studies they are enrolled for.

In this study, we examined the role of sense of coherence, study engagement and self-efficacy as a set of positive psychological attributes influencing third year level, higher education, working ODL students' general levels of satisfaction with their studies and employability.

\section{Sense of Coherence}

Sense of coherence is developed through the process of coming to understand one's life experiences in terms of their comprehensibility, manageability and meaningfulness (Antonovsky, 1991). Sense of coherence is internalised when life experiences are characterised by the individual's active participation in shaping outcomes, and a perceived balance between punishment and reward, success and failure (Marx, 2011).

Comprehensibility. Comprehensibility refers to (a) the extent to which individuals perceive incoming stimuli as making cognitive sense (having a certain logic in the sequence of events), (b) experiencing a degree of consistency from one experience to another, and (c) that in general, inexplicable events do not occur (Antonovsky, 1987; De Villiers, 2009). Information that is ordered, consistent, structured and clear (rather than noisy, chaotic, disordered, random, accidental and unpredict- 
able) leads to high levels of a sense of coherence (Antonovsky, 1987; De Villiers, 2009).

Manageability. Manageability refers to the extent to which people perceive that there are resources at their disposal that are adequate to meet the demands posed by stimuli. These resources may include resources under the individual's own control or resources controlled by legitimate others, that is, friends, colleagues, or God, within an environmental context (Antonovsky, 1987; Marx, 2011).

Meaningfulness. Meaningfulness, the emotional and motivational component (and counterpart of comprehensibility) of a person's sense of coherence, is experienced when events tend to be viewed as challenges worthy of emotional investment (Signe \& Solve, 2005).

In line with the arguments of Antonovsky $(1987,1991)$ and Marx (2011), we propose that a student who has a strong belief that the world (and their studies) makes sense (comprehensibility), is probably more likely to view himself/herself as being equal to the demands of living (manageability), compared to a student who sees the world (and their studies) as a place (thing) without rhyme or reason. By the same token, a student who lacks seeing the usefulness of committing to the activities of life or their studies (meaningfulness), is not likely to be motivated to participate in shaping events (such as their studies or writing an examination), even if the situation is perceived to be manageable.

\section{Study Engagement}

As a positive psychological construct, engagement is viewed as a positive, fulfilling and work-related state of mind that is characterised by vigour, dedication (efficacy) and absorption (Schaufeli, Salanova, González-Romá, \& Bakker, 2002). Vigour is characterised by high levels of energy and mental resilience while working (or studying), the willingness to invest effort in one's work (or studies), and persistence in the face of difficulties. This energy can also relate to the level of mental effort or mental strength that individuals can put into doing something. Dedication or efficacy is characterised by a sense of significance, enthusiasm, inspiration, pride and challenge, and the willingness of people to expend considerable time and effort in doing something meaningful. Absorption refers to the cognitive aspect where individuals are fully focused on something and experience a high level of concentration while performing a task. This concept includes being happily engrossed in one's work, so that time seems to pass quickly and one has difficulties in detaching oneself from work (Coetzer \& Rothmann, 2007; Marx, 2011).

In line with the arguments of Van den Berg, Manias, and Burger (2008) and Marx (2011), we propose that engaged students are typically characterised by (a) the willingness to take initiative and self-direct their lives, (b) the ability to generate their own positive feedback and so encourage themselves, (c) engagement in activities outside of their employment and studies, (d) agreement in values and norms with those of the organisation for which they work and the institution at which they pursue their studies, (e) the ability to intrinsically link fatigue to an overall sense of satisfaction, ( $f$ ) the ability to extricate themselves from their work to avoid becoming "burnt out", $(\mathrm{g})$ not being enslaved to their job or studies, and (h) the pursuit of outside interests. Engagement helps individuals derive benefits from stressful work (Britt, Adler, \& Bartone, 2001) and has been shown to be positively related to commitment (Demerouti, Bakker, De Jonge, Janssen, \& Schaufeli, 2001) and perfor- mance (Aktouf, 1992). Engagement is an energetic involvement with work or a task that builds professional efficacy (De Villiers, 2009).

\section{Self-efficacy}

Self-efficacy is the belief people have in their capabilities to perform in a certain way or engage in a specific behaviour to achieve their desired goals. It is the belief that people are able to perform the actions required to manage difficult or novel tasks and to cope with the adversity associated with demanding situations (Bandura, 1986; Kreitner \& Kinicki, 2004; Kreitner, Kinicki, \& Buelens, 2002). Unlike efficacy, which is the power to produce an effect, self-efficacy is the belief that people have the power to produce that effect (Bandura, 1997). Although this belief could be accurate or inaccurate, efficacy beliefs influence people's self-confidence and self-esteem, which in turn influence how they think, feel, motivate themselves and act (Bandura, 1995; Onyishi \& Ogbodo, 2012; Oosthuizen, 1998). In the higher education context, there are three different levels at which perceived self-efficacy operates as an important contributor to academic development. Students' beliefs in their efficacy, to regulate their own learning and to master academic activities, determine their aspirations, level of motivation, academic accomplishments and employability satisfaction. Lecturers' beliefs in their personal efficacy to motivate and promote learning affect the types of learning environments they create and the level of academic progress their students achieve in their study and employability satisfaction. Colleges' beliefs in their collective instructional efficacy contribute significantly to their schools' level of academic achievement (Bandura, 1993).

In line with the reasoning of the research literature, we propose that positive thoughts about one's studies relate to the efficacy beliefs in one's ability to successfully pursue study activities (such as writing the examination) and one's perceived employability. Positive self-efficacy beliefs are shown to link empirically to stronger career exploration (and study) plans and employability satisfaction (Austin \& Cilliers, 2011; Ochs \& Roessler, 2004) and study engagement (Olwage, 2012). As self-efficacy reliably predicts the scope of career options considered, occupational interests, career decision-making, perseverance in difficult fields and personal effectiveness, it has been related to the pursuit of entrepreneurial activity and employability satisfaction (Markman, Balkin, \& Baron, 2002; Olwage, 2012).

Higher levels of self-efficacy are associated with lower levels of stress, anxiety, perception of barriers and an increase in problem-solving appraisal (Bandura, 2000; Betz, 2004; Lent, Hackett, \& Brown, 2000; Paa \& McWhirtner, 2000) and slower withdrawal from activities (Betz, 2004; Betz \& Luzzo, 1996; Mau, 2003). Persons with positive career self-efficacy beliefs also have greater levels of self-esteem and internal control beliefs (Brown, Reedy, Fountain, Johnson, \& Dichiser, 2000; Paulsen \& Betz, 2004).

\section{Study and Employability Satisfaction}

In the context of the present study, we define study satisfaction as an affective or emotional response toward one's studies. This response could lead toward feelings of satisfaction or dissatisfaction (Oduaran, 2011). In the distance higher education literature (Bolliger \& Halupa, 2012), student satisfaction is regarded as an important concept because of its importance in increasing students' levels of motivation, engagement, learning, 
performance, and success. Research shows that as individuals' levels of satisfaction increase, their absenteeism from the institutional-related jobs or tasks also tends to decrease (Kreitner \& Kinicki, 2010). Satisfaction is also believed to be one of the most significant contributors to an individual's overall thoughts and feelings about quitting a job or task (Fried, Shirom, Gilboa, \& Cooper, 2008). Students' perceptions of the usefulness (or meaningfulness) and value of a study-related tasks, and self-efficacy have been indicated as factors influencing their satisfaction (Bolliger \& Halupa, 2012; Liaw, 2008; Lin, Lin, \& Laffey, 2008; Sahin \& Shelley, 2008).

Employability satisfaction is defined as the self-perceived level of satisfaction individuals have in terms of their beliefs that they have the attributes, skills, knowledge, experience and occupational expertise to create or attract employment with ease (Coetzee \& Schreuder, 2011). Employability satisfaction, therefore, represents individuals' self-efficacious beliefs in their capabilities of securing employment. Bandura (2000) and Van der Velde and Van den Berg (2003) suggest that employability is largely dependent on self-efficacy, which in turn, has been shown to be positively related to job search behaviour and positive employment outcomes (Kanfer, Wanberg, \& Kantrowitz, 2001).

\section{Objective of the Study}

The objective of the study was to explore whether students' sense of coherence, study engagement and self-efficacy significantly related to their satisfaction with current studies and self-perceived employability. The increasing concerns about students' pass and throughput rates, their employability, and the high risk associated with their absence from final examinations clearly underscore the need for research on how these psychological attributes impact higher education students' general levels of satisfaction with their studies and employability.

The specific research questions were:

- Is there a significant and positive relationship between students' sense of coherence, study engagement and self-efficacy, and their study and employability satisfaction?

- Do students' sense of coherence, study engagement and self-efficacy significantly predict their study and employability satisfaction?

\section{Method}

\section{Participants}

The participants were a convenience sample of 127 adults employed in the South African Service Industry who were enrolled for third year level undergraduate studies in Industrial and Organisational Psychology at a higher education distance learning institution. The sample predominantly constituted $66 \%$ Blacks and $34 \%$ Whites, and $71 \%$ women in the entry and establishment phases of their careers, with an age range of 25-40 years $(70 \%)$. The sample of participants were employed at management/supervisory (52\%) and staff level positions (48\%)

\section{Measurements}

Sense of Coherence. Sense of coherence was measured by using the Orientation to Life Questionnaire (OLQ) (Antonovsky, 1987). The OLQ is a self-rated, multi-factoria measure that contains three subscales (comprehension, manageability, meaningfulness) consisting of a total of 29 items. Responses are measured on a seven-point likert-type scale. The questionnaire is regarded as a reliable, valid and cross-cultur- ally applicable instrument that has been extensively studied in multiple settings in the South African context, with diverse populations and different languages (Bezuidenhout \& Cilliers, 2010; Van der Collf \& Rothmann, 2009). The Cronbach's alpha coefficients (internal consistency reliability) for the 3 subscales (as obtained for the sample of the current study) were as follows: comprehension (.68), manageability (.43), meaningfulness (.77).

Study engagement. An adapted version of the Utrecht Work Engagement Scale (UWES) (Schaufeli et al., 2002) was used to measure the levels of study engagement. The term "work" in the various items was replaced with the term "study" in the adapted version of the scale. The UWES includes 17 items measuring the engagement construct on 3 dimensions: vigour, dedication and absorption which are scored on a seven-point frequency-rating scale, ranging from zero (0) (never) to six (6) (every day). Confirmatory factor analysis (Schaufeli et al., 2002) demonstrated the factorial validity of the UWES. The Cronbach's alpha coefficients (internal consistency reliability) for the 3 subscales (as obtained for the sample of the current study) were as follows: vigour (.89), dedication (.84), absorption (.89).

Self-efficacy. Self-efficacy was measured by using the Self-Efficacy Scale (SES) (Sherer \& Maddux, 1982). The SES consists of 27 items. The statements deal with attitudes and feelings that people might have of themselves and their performance in a variety of tasks. Each item is answered on a seven-point likert-type scale varying between one (1) (strongly agree) and seven (7) (strongly disagree), while four (4) indicates a midpoint. Low scores indicate a high level of self-efficacy (Marais, 1997). Cronbach's alpha coefficients (internal consistency reliabilities) vary between .71 and .86 . The overall Cronbach's alpha coefficient for the scale (as obtained for the sample of the current study) was .79. Research in South Africa confirms the construct and criterion validity of the scale (Marais, 1997; Oosthuizen, 1998).

Biographical questionnaire. The biographical questionnaire contained 2 additional single-items measured on a four-point likert-type scale, ranging from very dissatisfied to highly satisfied. The 2 items measured participants' perceptions of their level of general satisfaction with their current studies ("How would you describe your general level of satisfaction with your current studies?") and employability satisfaction ("How would you describe your employability, that is, do you believe you have the attributes, skills, knowledge, experience and occupational expertise to create or attract employment with ease?').

\section{Research Procedure}

Ethical clearance and permission to conduct the study were obtained from the management of the higher education institution that participated in the study. Questionnaires were mailed to the total population of 3,000 students who were registered for third year level studies in Industrial and Organisational Psychology at the higher education institution for the particular year, yielding a response rate of $4 \%(n=127)$. The postal facilities of the institution were used to mail these questionnaires. Each questionnaire included a cover letter to obtain informed consent from the participants to use their responses for research purposes only. The cover letter explained the purpose of the research, procedure, potential benefits, confidentiality, anonymity, voluntary participation and withdrawal. Participants were 
requested to complete the questionnaires and return them by mail to the researcher using an enclosed return envelope.

\section{Statistical Analyses}

In the light of the exploratory nature of the research design, descriptive statistics (means, standard deviations and Cronbach's alpha coefficients), correlational and standard multiple regression analyses were performed to assess the relationship between the variables of concern to the present study. In order to counter the probability of a Type I error, it was decided to set the significance value for interpreting the results at a $95 \%$ confidence interval level $(p=.05)$. For the purposes of this study, $r$-values equal to and larger than .30 (medium effect) and $R^{2}$ values of $=.12$ (small practical effect) and $=.13=.25$ (medium practical effect) $(F p=.05)$ (Cohen, 1992) were also considered in the interpretation of the results.

\section{Results}

\section{Descriptive Statistics: Means, Standard Deviations and Frequencies}

Table 1 shows that the participants obtained the highest mean scores on the OLQ manageability $(M=50.10 ; S D=6.98)$ and UWES vigour $(M=32.46$; $S D=9.54)$ and absorption $(M=$ 32.30; $S D=10.71$ ) variables. The participants obtained the lowest mean scores on the OLQ meaningfulness $(M=44.53 ; S D=$ 8.31) and UWES dedication $(M=22.96 ; S D=5.73)$ variables. The high mean scores obtained on the SES (self-efficacy) suggest a low level of self-efficacy $(M=60.61 ; S D=14.44)$.

Table 2 shows that most of the participants were generally satisfied to highly satisfied with their current studies (87\%) and their self-perceived level of employability (81\%).

\section{Correlations}

Table 3 shows that meaningfulness (OLQ) significantly and positively correlated with the participants' satisfaction with their current studies ( $r=.32 ; p=.001$; medium practical effect) and their self-perceived employability $(r=.22 ; p=.01$; small practical effect). In terms of study engagement (UWES), vigour ( $r=$ $.22 ; p=.01$; small practical effect), dedication $(r=.32 ; p=.001$; medium practical effect) and absorption ( $r=.23 ; p=.01$; small practical effect) correlated significantly and positively with the participants' satisfaction with their current studies. Only dedication correlated significantly and positively with the participants' employability satisfaction ( $r=.22 ; p=.01$; small practical effect). Self-efficacy did not correlate significantly with the participants' satisfaction with their current studies and their self-perceived employability.

\section{Multiple Regression Analyses}

As shown in table 4, the regression analyses of the participants' satisfaction with their current studies produced a statistically significant model in terms of the OLQ (sense of coherence) variables $\left(R^{2}=.15 ; \mathrm{F} p=.001\right.$; medium practical effect), explaining $15 \%$ of the variance in the satisfaction with current studies variable. In terms of the UWES (study engagement) variables, a statistically significant model $\left(R^{2}=.10 ; \mathrm{F} p=.01\right.$; medium practical effect) was produced, explaining $10 \%$ of the variance in the satisfaction with current studies variable. No statistically significant regression model was obtained in terms of the self-efficacy (SES) variable.

Table 4 shows that in terms of the sense of coherence (OLQ) variables, only meaningfulness $(\beta=.46 ; p=.00)$ contributed significantly in explaining the variance in the satisfaction

Table 1

Descriptive Statistics: Means, Standard Deviations and Cronbach Alpha Coefficients

\begin{tabular}{lccc}
\hline Scale & Mean & SD & $\begin{array}{c}\text { Cronbach Alpha } \\
\text { coefficient }\end{array}$ \\
\hline Sense of coherence (OLQ) & & & \\
Comprehension & 49.59 & 8.93 & .68 \\
Manageability & 50.10 & 6.98 & .43 \\
Meaningfulness & 44.53 & 8.31 & .77 \\
Study engagement (UWES) & & & .89 \\
Vigour & 32.46 & 9.54 & .84 \\
Dedication & 22.96 & 5.73 & .89 \\
Absorption & 32.30 & 10.71 & .79 \\
Self-efficacy (SES) & 60.61 & 14.44 &
\end{tabular}

Note. $n=127$

Table 2

Frequencies of Single Item Scales - Satisfaction with Current Studies and Employability Satisfaction

\begin{tabular}{lcccl}
\hline Scale & Very dissatisfied & Dissatisfied & Satisfied & Highly satisfied \\
\hline Satisfaction with current studies & $1 \%(n=2)$ & $12 \%(n=15)$ & $59 \%(n=75)$ & $28 \%(n=35)$ \\
Employability satisfaction & $1 \%(n=2)$ & $18 \%(n=23)$ & $58 \%(n=73)$ & $23 \%(n=29)$ \\
\hline
\end{tabular}

Note. $\mathrm{n}=127$ 
Table 3

Spearman Correlation Coefficient Matrix for Sense of Coherence, Study Engagement and Self-Efficacy in Relation to Satisfaction with Current Studies and Employability Satisfaction

\begin{tabular}{lcc}
\hline Scale & Satisfaction with current studies & Employability satisfaction \\
\hline Sense of coherence (OLQ) & & $.08 \mathrm{n} / \mathrm{s}$ \\
Comprehension & $-.03 \mathrm{n} / \mathrm{s}$ & $.01 \mathrm{n} / \mathrm{s}$ \\
Manageability & $-.41 \mathrm{n} / \mathrm{s}$ & $.22^{* *}+$ \\
Meaningfulness & $.32^{* *}++$ & $.10 \mathrm{n} / \mathrm{s}$ \\
Study engagement (UWES) & & $.22^{* *}+$ \\
Vigour & $.22^{* *}+$ & $.11 \mathrm{n} / \mathrm{s}$ \\
Dedication & $.32^{* *}++$ & $-.18 \mathrm{n} / \mathrm{s}$ \\
Absorption & $.23^{* *}+$ & $-.17 \mathrm{n} / \mathrm{s}$ \\
Self-efficacy (SES) &
\end{tabular}

Note. ${ }^{* * *} p \leq .001^{* *} p \leq .01^{*} p \leq .05$ (two-tailed) $\mathrm{n} / \mathrm{s}$ : not significant; $+++r \geq .50$ (large practical effect size) $++r \geq .30 \leq .49$ (medium practical effect size) $+r \leq .29$ (small practical effect size); $\mathrm{n}=127$

Table 4

Standard Multiple Regression Analyses for Sense of Coherence and Study Engagement (Independent Variables) on Satisfaction with Current Studies (Dependent Variable)

\begin{tabular}{|c|c|c|c|c|c|c|c|c|}
\hline \multirow[b]{2}{*}{ Variable } & \multicolumn{5}{|c|}{ Standardised coefficient } & \multicolumn{3}{|c|}{ Adjusted } \\
\hline & B & SE & $d f$ & $F$ & $p$ & $F$ & $R^{2}$ & $R$ \\
\hline Comprehension (OLQ) & -0.13 & 0.11 & 1 & 1.25 & .27 & $8.23^{* * *}$ & $.15++$ & .17 \\
\hline Manageability (OLQ) & -0.20 & 0.10 & 1 & 3.19 & .08 & & & \\
\hline Meaningfulness (OLQ) & 0.46 & 0.08 & 1 & 29.89 & $.00 * * *$ & & & \\
\hline Vigour (UWES) & 0.05 & 0.23 & 1 & 0.04 & .85 & $5.35 * *$ & $.10+$ & .11 \\
\hline Dedication (UWES) & 0.47 & 0.17 & 1 & 7.80 & $.01^{* *}$ & & & \\
\hline Absorption (UWES) & -0.22 & 0.25 & 1 & 0.76 & .39 & & & \\
\hline
\end{tabular}

Note. ${ }^{* *} p \leq .001 ;{ }^{* *} p \leq .01 ;{ }^{*} p \leq .05 ;+R^{2} \leq .12$ (small practical effect size); $++R^{2} \geq .13 \leq .25$ (medium practical effect size); +++ $R^{2} \geq .26$ (large practical effect size); $\mathrm{n}=127$.

with current studies variable. In terms of the student engagement (UWES) variables, only dedication $(\beta=.47 ; p=.01)$ contributed significantly in explaining the variance in the satisfaction with current studies variable.

As shown in Table 5, the regression analyses of the participants' employability satisfaction produced a statistically significant model in terms of the OLQ (sense of coherence) variables $\left(R^{2}=.08 ; \mathrm{F} p=.01\right.$; small practical effect), explaining $8 \%$ of the variance in the employability satisfaction variable. In terms of the UWES (study engagement) variables, a statistically significant model $\left(R^{2}=.11 ; \mathrm{F} p=.001\right.$; small practical effect) was produced, explaining $11 \%$ of the variance in the employability satisfaction variable. No statistically significant regression model was obtained in terms of the self-efficacy (SES) variable.

\section{Discussion}

Overall, the results indicated that the participating students' perceptions of the meaningfulness of their studies significantly predicted their satisfaction with their current studies and self-perceived employability. These findings suggest that the extent to which the participating students felt that their lives (and their studies) made sense on an emotional and not just a cognitive level, and that the demands of their lives and studies were worthy of commitment, influenced the extent of their study and employability satisfaction. According to Nelson and Simmons (2003), perceiving work or a task as meaningful leads to eustress which promotes engagement or work devotion even if the situation is demanding.

In terms of the participants' study engagement, the results showed that their levels of vigour, dedication and absorption were significantly related to their satisfaction with their current studies. The participants' sense of dedication to their studies significantly predicted their satisfaction with their current studies and self-perceived employability. Meaningfulness and dedication are related to individuals' motivation for pursuing a certain course of action (De Villiers, 2009). Research by De Villiers (2009) indicates a positive and significant relationship between individuals' sense of dedication and meaningfulness. According to Boyd (2004), having a clear understanding as to why one is taking a particular course or programme is a key factor for sustaining the motivation of successful students.

Participants' sense of self-efficacy did not relate significantly to their satisfaction with their current studies and self-perceived 
Table 5

Standard Multiple Regression Analyses for Sense of Coherence and Study Engagement (Independent Variables) on Employability Satisfaction (Dependent Variable)

\begin{tabular}{|c|c|c|c|c|c|c|c|c|}
\hline \multirow[b]{2}{*}{ Variable } & \multicolumn{5}{|c|}{ Standardised coefficient } & \multicolumn{3}{|c|}{ Adjusted } \\
\hline & B & SE & df & $\mathrm{F}$ & $\mathrm{p}$ & $\mathrm{F}$ & $\mathrm{R}^{2}$ & $\mathrm{R}$ \\
\hline Comprehension (OLQ) & 0.05 & 0.12 & 1 & 0.20 & .66 & 4.36 ** & $.08+$ & .10 \\
\hline Manageability (OLQ) & -0.18 & 0.17 & 1 & 1.07 & .30 & & & \\
\hline Meaningfulness (OLQ) & 0.33 & 0.11 & 1 & 9.19 & $.003^{* *}$ & & & \\
\hline Vigour (UWES) & -0.34 & 0.23 & 1 & 2.06 & .15 & $6.07^{* * *}$ & $.11+$ & .13 \\
\hline Dedication (UWES) & 0.60 & 0.15 & 1 & 15.60 & $.00^{* * *}$ & & & \\
\hline Absorption (UWES) & -0.05 & 0.25 & 1 & 0.04 & .85 & & & \\
\hline
\end{tabular}

Note. ${ }^{* * *} \mathrm{p} \leq .001 ;{ }^{* *} \mathrm{p} \leq .01 ;{ }^{*} \mathrm{p} \leq .05 ;+\mathrm{R}^{2} \leq .12$ (small practical effect size); ++ $\mathrm{R}^{2} \geq .13 \leq .25$ (medium practical effect size); + ++ $\mathrm{R}^{2} \geq .26$ (large practical effect size); $\mathrm{n}=127$.

employability. Overall, the participants' self-efficacy, that is, their confidence in their ability to organise and perform certain actions that are required to maintain, organise and execute their current studies, seemed to be low. Furthermore, the participants' confidence in their abilities to mobilise the required level of motivation, and the cognitive resources and actions necessary to control the demands posed by their studies, seemed to be overall lacking. The low self-efficacy scores of the participants could be attributed to their probable inability to strike an appropriate balance between work time and study time (Knight, Corbett, Smith, Watkins, Hardy, \& Jones, 2012) and the participants feeling less confident (and more anxious) about the probability of successfully completing their ODL studies. Oosthuizen (2006) posits that low self-efficacy scores often point to feelings of not being able to master, or feeling anxious about mastering a specific task (such as those related to one's studies, preparing for, and writing an examination). The low self-efficacy scores thus seem to corroborate the research by Tladi (2009) on examination absenteeism in the ODL context. Tladi (2009) found that unpreparedness for the examination was a major factor for examination absenteeism, mostly resulting from a lack of confidence (low self-efficacy) and motivation leading to not spending enough time on their preparation for the examination.

\section{Limitations and Recommendations for Further Study}

The limitations of the present study should be borne in mind when interpreting the results. The study was limited to a relative small sample of distance learning students in a particular higher education setting and disciplinary field of study. As such, the findings cannot be generalised to other institutional and disciplinary contexts. This study could be replicated with larger samples comprising a broader representation of age, race and gender groups, and disciplinary fields of study in the ODL context. Other studies could include students' pass rates, exam absenteeism and other success indicators in investigating the relationship between their sense of coherence, study engagement, self-efficacy, and their study and employability satisfaction. Notwithstanding the limitations of the study, we believe that the findings from the study contributed valuable new knowledge to the South African ODL higher education context. The insights derived from the study deepened understanding of the positive psychological attributes that potentially influence student success rates and examination presenteeism.

\section{Conclusions and Implications for Practice}

The lack of a significant relationship observed between the participating students' sense of self-efficacy, comprehensibility and manageability and their satisfaction with their current studies and self-perceived employability, suggests that cognitive aspects such as the students' beliefs in their performance capabilities (self-efficacy), the perceived logic, order and predictability of their studies (comprehensibility), and their perceptions of having control over, or the resources to deal successfully with their studies (self-efficacy and manageability), were less important than their emotional devotion to their studies in increasing their satisfaction levels.

The results seem to further confirm this observation when considering that although the participating students had a seemingly low sense of self-efficacy, they were overall satisfied to highly satisfied with their current studies and employability. It appears thus from the results that tapping into the emotional (affective) and motivational side of students is important in increasing their levels of study and employability satisfaction. A high sense of perceived meaningfulness and dedication seems to positively enhance student satisfaction levels.

The research findings have implications for educators in the ODL context. The prominent influencing effect of students' dedication to and perceived meaningfulness of their studies on their satisfaction levels, suggests the need for making students aware of the fit between a particular course or programme and their unique life or career goals and desires. Learner support should cover assistance in helping students identify specific reasons for their study (Xiao, 2012), become more aware of their own career interests and how these fit in with their studies, and the payoffs and benefits in pursuing and successfully completing their studies in a particular course or programme. Olwage (2012) found that students' sense of dedication was significantly associated with the availability of information about occupations, self-awareness, and the information-gathering and decision-making process. Students perceiving that their studies make sense on an emotional and cognitive level may consequently be more motivated, and generally, more willing to dedicate their energy and effort to deal with perceived difficulties (such as writing an examination). They may generally feel inspired by the challenges stemming from their studies and derive a sense of pride from their efforts, resulting in higher levels of satisfaction. Although not empirically investigated in this study, we propose that high student motivational and satisfac- 
tion levels may also lead to a decrease in examination absenteeism. Students without specific reasons for their studies (and the perceived payoffs of investing energy and effort in one's studies) are often not able to sustain the motivation to persevere with their studies (even if they have the confidence in their capability to be successful) (Xiao, 2012), which in turn may impact their retention, exam presenteeism and success (Tladi, 2009).

The results of the present study further seem to suggest that apart from enhancing ODL students' sense of dedication to and the perceived meaningfulness of their studies in order to improve their satisfaction and probably their retention, exam presenteeism and completion rate, their self-efficacious beliefs of being successful in their studies need also to be considered in learner support initiatives. Learner support efforts need to focus on helping ODL students develop the confidence in their ability to successfully master the tasks and preparation associated with preparing for, and writing an examination, whilst striking a balance between work-family and study time, and the responsibility of fulfilling multiple roles.

\section{References}

Aktouf, O. (1992). Management and theories of organizations in the 1990s: Toward a critical radical humanism, Academy of Management Review, 17, 407-431.

Antonovosky, A. (1987). Unravelling the mystery of health: How people manage stress and stay well. San Francisco, CA: Jossey-Bass.

Antonovsky, A. (1991). Personality and stress: individual differences in the stress process. London, England: John Wiley.

Austin, K., \& Cilliers, F. V. N. (2011). The psychometric relationship between career thinking and salutogenic functioning amongst unemployed adults. South African Journal of Industrial Psychology, 37(1): Art. 969, 11 pages. http://dx.doi. org/10.4102/sajip.v37i1.969

Bandura, A. (1986). Social foundation of thought and action: $A$ social-cognitive theory. Englewood Cliffs, NJ: Prentice Hall.

Bandura, A. (1989). Social cognitive theory. Annals of child development, 6, 1-60.

Bandura, A. (1993). Perceived self-efficacy in cognitive development and functioning. Educational Psychologist, 28(2), 117-148.

Bandura, A. (1995). Exercise of personal and collective efficacy in changing societies. In A. Bandura (Ed.), Self-efficacy in changing societies (pp. 1-45). New York, NY: Cambridge University Press.

Bandura, A. (1997). Self-efficacy: The exercise of control. New York, NY: Freeman.

Bandura, A. (2000). Exercise of human agency through collective efficacy. Current Directions in Psychological Science, 9, 75-78. http://dx.doi.org/10.1111/1467-8721.00064

Betz, N. E. (2004). Contributions of self-efficacy theory to career counselling: A personal perspective. The Career Development Quarterly, 52, 340-353.

Betz, N. E., \& Luzzo, D. A. (1996). Career assessment and the Career Decision-making Self-efficacy Scale. Journal of Career Assessment, 4(4), 413-428. http://dx.doi. org/10.1177/ 106907279600400405

Bezuidenhout, A., \& Cilliers, F. V. N. (2010). Burnout, work engagement and sense of coherence in female academics in higher-education institutions in South Africa. South African
Journal of Industrial Psychology, 36(1), Art.\#872.10 pages. doi: 10.4102/sajip.v36i1.872.

Bolliger, D. U., \& Halupa, C. (2012). Student perceptions of satisfaction and anxiety in an online doctoral program. Distance Education, 1(5), 81-98.

Boyd, D. (2004). The characteristics of successful online students. New Horizon in Adult Education, 18(2), 31-39.

Britt, T. W., Adler, A. B., \& Bartone, P. T. (2001). Deriving benefits from stressful events: The role of engagement in meaningful work and hardiness, Journal of Occupational Health Psychology, 6, 53-63.

Brown, C., Reedy, D., Fountain, J., Johnson, A., \& Dichiser, T. (2000). Battered women's career decision-making self-efficacy: Further insights and contributing factors. Journal of Career Assessment, 8(3), 251-265. Retrieved from http://dx.doi.org/10. 1177/106907270000800304

Coetzee, M., \& Schreuder, A. M. G. (2011). The relation between career anchors, emotional intelligence and employability satisfaction among workers in the service industry. Southern African Business Review, 15(3), 76-97.

Coetzer, C. F., \& Rothmann, S. (2007). Job demands, job resources and work engagement of employees in a manufacturing organisation, Southern African Business Review, 11(1), 17-32.

Cohen, J. (1992). Quantitative methods in psychology: a power primer. Psychological Bulletin, 112(1), 153-159.

Demerouti, E., Bakker, A. B., De Jonge, J., Janssen, P. P. M., \& Schaufeli, W. B. (2001). Burnout and engagement at work as a function of demands and control, Scandinavian Journal of Work Environment \& Health, 27, 279-286.

De Villiers, M. (2009). The relationship between employee wellness and career anchors (Unpublished master's dissertation. University of South Africa, Pretoria, South Africa.

Ewen, R. B. (2003). An Introduction to Theories of Personality. New Jersey: Lawrence Erlbaum.

Fried, Y., Shirom, A., Gilboa, S., \& Cooper, C. L. (2008). The mediating effects of job satisfaction and propensity to leave on role stress-job performance relationship: Combining meta-analysis and structural equation modelling. International Journal of Stress Management, 11, 305-328.

Houdmont, J., \& Leka, S. (2010). Contemporary Occupational Health Psychology: Global Perspectives on research and practice. West Sussex: John Wiley.

Kanfer, R., Wanberg, C. R., \& Kantrowitz, T. M. (2001). Job search and employment: A personality-motivational analysis and meta-analytical review. Journal of Applied Psychology, 86(5), 837-855.

Knight, J., Corbett, A., Smith, C., Watkins, B., Hardy, R., \& Jones, G. (2012). "What made me stay?" A review of the reasons student nurses enrolled in a Bachelor of Nursing programme completed their studies: A descriptive phenomological study. Nurse Education Today. doi:10.1016/j.nedt.2012.03.007

Kreitner, R., \& Kinicki, A. (2004). Organizational behavior (6th ed.). New York, NY: McGraw-Hill.

Kreitner, R., \& Kinicki, A. (2010). Organizational behavior (9th ed.). New York, NY: McGraw-Hill

Kreitner, R., Kinicki, A., \& Buelens, M. (2002). Organizational behavior. New York, NY: McGraw-Hill.

Lent, R. W., Hackett, G., \& Brown, S. D. (2000). Contextual supports and barriers to career choice: A social cognitive analy- 
sis. Journal of Counseling Psychology, 47, 36-49. http://dx. doi.org/10.1037/0022-0167.47.1.36

Liaw, S. (2008). Investigating students' perceived satisfaction, behavioural intention, and effectiveness of e-learning: A case study of the Blackboard system. Computers \& Education, 51, 864-873.

Lin, Y., Lin, G., \& Laffey, J. M. (2008). Building a social and motivational framework for understanding satisfaction in online learning. Journal of Educational Computing Research, 38, 1-27. doi:10.2190/EC.38.1

Marais, C. P. (1997). Salutogenesis as paradigm in change management (Unpublished master's dissertation). University of South Africa, Pretoria, South Africa.

Markman, G. D., Balkin, D. B., \& Baron, R. A. (2002). Inventors and new venture formation: The effects of general self-efficacy and regretful thinking. Entrepreneurship Theory and Practice, 27, 149-165.

Marx, A. A. (2011). The role of positive psychology constructs in employee coping (Unpublished master's dissertation). University of South Africa, Pretoria, South Africa.

Mau, W. (2003). Factors that influence persistence in science and engineering career aspirations. The Career Development Quarterly, 51, 234-243.

Nelson, D. L., \& Simmons, B. L. (2003). Health psychology and work stress: A more positive approach. In J. C. Quick \& L. E. Tetrick (Eds.), Handbook of occupational health psychology (pp. 97-119). Washington, DC: American Psychological Association.

Ochs, L. A., \& Roessler, R. T. (2004). Predictors of career exploration intentions: A social cognitive career theory perspective. Rehabilitation Counselling Bulletin, 47(4), 224-233. Retrieved from http://dx.doi.org/ 10.1177/00343552040470040401

Oduaran, A. B. (2011). Service quality and students' satisfaction with the professional teacher development programmes by distance mode in a South African university. South African Journal of Higher Education, 25(7), 1429-1446.

Olwage, D. (2012). Predictors of burnout and engagement of university students (Unpublished master's dissertation). North-West University, Potchefstroom, South Africa.

Onyishi, I. E., \& Ogbodo, E. (2012). The contributions of self-efficacy and perceived organisational support when taking charge at work. South African Journal of Industrial Psychology, 38(1), Art.\#979, 11 pages. http://dx.doi.org./10.4102/sajip.v38i1.979

Oosthuizen, R. M. (1998). Brandweermanne in 'n plaaslike owerheid se hantering van stres: 'n fortigene benadering. [Coping of Stress by fire fighters in a local government: $A$ fortigenic approach.] (Unpublished master's dissertation). Department of Industrial and Personnel Psychology, North-West University, Potchefstroom, South Africa.

Oosthuizen, R. M. (2006). Stress-management strategies of firefighters: A fortigenic approach. Southern African Business Review, 10(3), 94-114.

Paa, H. K., \& McWhirter, E. H. (2000). Perceived influences on high school students' current career expectations. Career Development Quarterly, 49, 29-44.

Paulsen, A. M., \& Betz, N. E . (2004). Basic confidence predictors of career decision-making self-efficacy. The Career Development Quarterly, 52, 354-362.

Pityana, B. (2009, June). Open distance learning in the developing world: Trends, progress, and challenges. Keynote speech delivered at 23rd ICDE World Conference on Open Learning and Distance Education, the Netherlands.

Pool, L. D., \& Sewell, P. (2007). The key to employability: developing a practical model of graduate employability. Education \& Training, 49(4), 277-289.

Prinsloo, P., \& Subotzky, G. (2011). Towards a framework and strategy for enhancing student success, retention, graduation and satisfaction at Unisa. Final Report Task Team 6, University of South Africa, Pretoria, South Africa.

Sahin, I., \& Shelley, M. (2008). Considering students' perceptions: The distance education student satisfaction model. Educational Technology and Society, 11(3), 216-223.

Schaufeli, W. B., Salanova, M., González-Romá, V., \& Bakker, A. B. (2002). The measurement of engagement and burnout and a confirmative analytic approach. Journal of Happiness Studies, 3, 71-92.

Sherer, M., \& Maddux, J. E. (1982). The self-efficacy scale: Construction and validation. Psychological reports, 51, 663-671.

Signe, A., \& Solve, E. (2005). Family caregivers' subjective experiences of satisfaction in dementia care: Aspects of burden, subjective health and sense of coherence. Scandinavian Journal of Caring Sciences, 19 (92), 157-168.

Snyder, C. R., Lopez, S. J., \& Pedrotti, J. T. (2010). Positive psychology: The scientific and practical explorations of human strengths (2nd ed.). Thousand Oaks, CA: Sage.

Strydom, F., Kuh, G., \& M. Mentz, M. (2010). Enhancing success in South Africa's higher education: Measuring student engagement. Acta Academica, 42(1), 259-278.

Tladi, L. (2009). UNISA exam absence survey report. Department of Information and Strategic Analysis, University of South Africa, Pretoria, South Africa.

Tomlinson, M. (2007). Graduate employability and student attitudes and orientations to the labour market. Journal of Education and Work, 20(4), 285-304.

Van den Berg, H., Manias, D., \& Burger, S. (2008). The influence of job-related factors on work engagement of staff at the University of the Free State, Acta Academica, 40(3), 85-114.

Van der Colff, J. J., \& Rothman, S. (2009). Occupational stress, sense of coherence, coping, burnout and work engagement of registered nurses in South Africa. South African Journal of Industrial Psychology, 35(1), Art.\#423, 10 pages. doi: 10.4102/sajip.v351L.423

Van der Velde, M., \& Van den Berg, P. (2003). Managing functional flexibility in a passenger transport firm. Human Resource Management Journal, 13(4), 45-55.

Xiao, J. (2012). Successful and unsuccessful distance language learners: An "affective" perspective. Open Learning, 27(2), 121-136. 